\title{
Efeito da soldagem nas propriedades mecânicas e metalúrgicas do aço API 5L X65
}

\author{
Effect of welding on the mechanical and metallurgical properties \\ of API 5L X65 steel
}

\author{
Rodrigo Fadrique ${ }^{1}$ \\ Jorge Luis Braz Medeiros ${ }^{2}$ \\ Luciano Volcanoglo Biehl ${ }^{3}$ \\ José de Souza ${ }^{4}$ \\ Carlos Otávio Damas Martins ${ }^{5}$
}

\section{Resumo}

Este estudo avaliou as propriedades mecânicas e metalúrgicas de uma junta de topo soldada em tubulação de aço API 5L X65, aço microligado, amplamente utilizado na indústria offshore. O procedimento inicia com o revestimento (cladding) da região a ser soldada e vizinhança com metal de adição, através do processo de soldagem TIG que também é utilizado nos diferentes passes de raiz. O revestimento da junta soldada foi realizado pelo processo SMAW. Esses procedimentos de soldagem foram avaliados com a utilização de corpos de prova, submetidos a ensaios mecânicos e metalúrgicos requeridos por normas aplicáveis à indústria offshore. Adicionalmente, foram realizados ensaios complementares, relacionados ao tamanho de grão austenítico na Zona Termicamente Afetada (ZTA) e Zona de Fusão (ZF). Concluiu-se que o procedimento de soldagem utilizado pode ser largamente aplicado na indústria, sem comprometimento significativo do metal base, ZTA e ZF, minimizando a necessidade de tratamentos térmicos posteriores.

Palavras-chave: Soldagem. Cladeamento. Microligado.

\begin{abstract}
This study evaluated the mechanical and metallurgical properties of a welded butt joint in API $5 \mathrm{~L}$ X65 steel pipe, microalloyed steel, widely used in the offshore industry. The procedure starts with the cladding of the region to be welded and the vicinity with filler metal, through the TIG welding process which is also used for the different root passes. The cladding of the welded joint is done by the SMAW process. These welding procedures were evaluated using specimens, submitted to the mechanical and metallurgical tests, required by standards applicable to the offshore industry. Additionally, there were performed some complementary tests, regarding to the austenitic grain size in the Heat Affected Zone (HAZ) and Fusion Zone (FZ). It was concluded that the welding procedure used can be widely applied in the industry without significant compromise of the base metal, HAZ and FZ, minimizing the need for subsequent heat treatments.
\end{abstract}

Keywords: Welding. Cladding. Microallyed.

1 Engenheiro mecânico pela Universidade Federal do Rio Grande (FURG), Rio Grande, RS, Brasil. ORCID: https://orcid.org/0000-00027986-4690. E-mail: rodrigo.fadrique@gmail.com

2 Doutor em Ciência e Tecnologia dos Materiais pela Universidade Federal do Rio Grande do Sul (UFRGS), Porto Alegre, RS. Professor na FURG. ORCID: https://orcid.org/0000-0003-3468-7632.E-mail: jorge.braz@furg.br

3 Doutor em Ciência e Tecnologia dos Materiais pela UFRGS. Professor na FURG. ORCID: https://orcid.org/0000-0002-5415-5863. E-mail: lucianobiehl@furg.br

4 Doutor em Processos de Fabricação na UFRGS. Professor da Fundação Escola Técnica Liberato Salzano Vieira da Cunha (FETLSVC), Novo Hamburgo, RS. ORCID: https://orcid.org/0000-0001-5888-840X. E-mail: josesouza@liberato.com.br

5 Doutor em Ciência e Tecnologia dos Materiais pela UFRGS. Professor Universidade Federal do Sergipe (UFS), São Cristóvão, SE, Brasil. ORCID: https://orcid.org/0000-0003-1418-3226. E-mail: carlosmartinsufs@gmail.com 


\section{Introdução}

A crescente demanda tecnológica no atual mercado de óleo e gás requer cuidados severos em relação às propriedades metalúrgicas e mecânicas dos materiais, principalmente na indústria offshore, onde há necessidade de materiais com alta confiabilidade. Nesse aspecto, destaca-se o American Petroleum Institute (API) que é referência mundial para normatização de processos, envolvendo a indústria de petróleo e gás natural, tanto offshore quanto onshore.

A norma API-5L é a referência para a especificação de tubulações que se referem à composição química, parâmetros de soldagem, soldabilidade, propriedades metalúrgicas, resistência mecânica, entre outras.

Quando da aplicação em estruturas navais ou offshore, em geral, há um controle rigoroso quanto às etapas de fabricação e operação das instalações, devido ao fato das operações serem realizadas em ambientes internacionais. Nesse aspecto, a normatização e classificação dessas estruturas atendem a International Maritime Organization (IMO) que é o braço naval da Organização das Nações Unidas (ONU). Este estudo tem como objetivo avaliar o efeito do aporte térmico, pela aplicação de múltiplos passes de sondagem e revestimento, nas propriedades metalúrgicas e mecânicas do aço API - 5L.

\section{Revisão bibliográfica}

Atualmente, o mercado consumidor de aços para transporte de óleo e gás natural demanda materiais com alta resistência mecânica aliada à boa transição dúctil frágil em temperaturas abaixo de zero.Devido a essas características, são utilizados em larga escala os aços de Alta Resistência e Baixa Liga (ARBL) que proporcionam a fabricação de dutos para transporte de elevadas pressões de óleo e gás, bem como a redução da espessura de parede dos mesmos (GIORGETTI et al., 2019). O desenvolvimento dos aços cresce no mundo, sendo os primeiros aços API fabricados na metade do século 20 até as modernas técnicas de fabricação nos dias de hoje. Afirma-se que, aliado à melhoria das propriedades mecânicas e soldabilidade do aço, essa evolução nos aços API contribui para redução dos custos de produção nas indústrias, onde os mesmos são utilizados, visto que, hoje, obtém-se tubos mais leves e fáceis de manusear e com espessura de paredes reduzida, o que garante uma quantidade menor de metal de solda depositado nas juntas (SAEDI; HAJJARI; SADROSSADAT, 2018). Na figura 1, observa-se a evolução dos aços ARBL, associando os mesmos com ao desenvolvimento dos processos de laminação controlada.

Figura 1 - Evolução e desenvolvimento dos aços ARBL

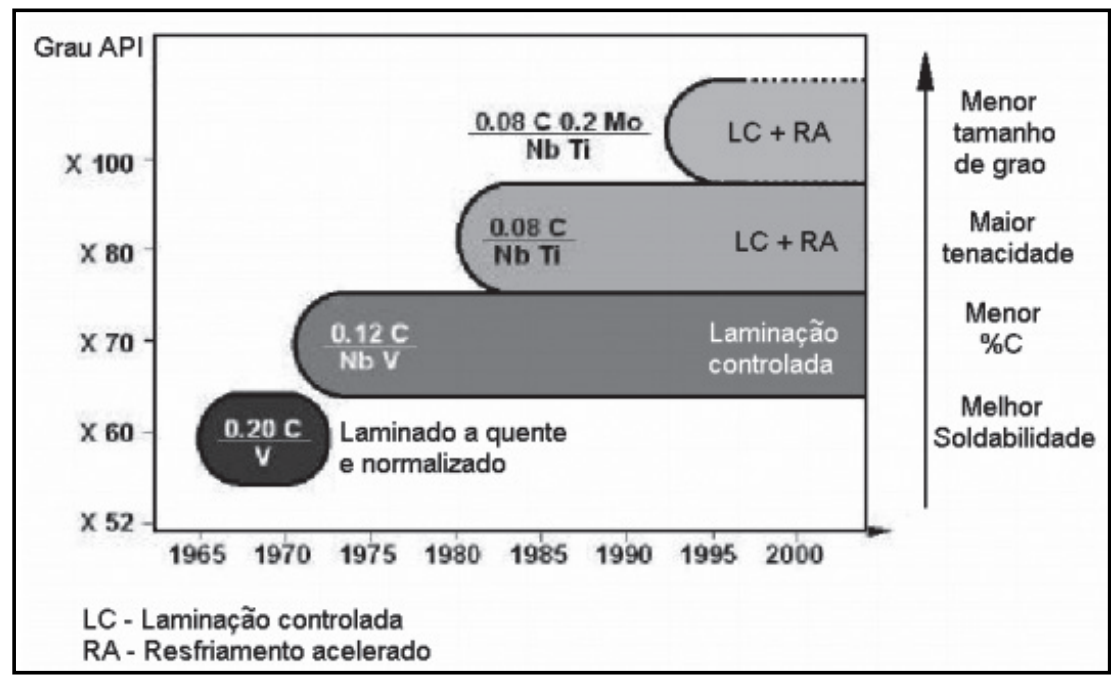

Fonte: Adaptado de Gorni e Mei (2003).

A microestrutura final dos aços ARBL está intimamente ligada com a forma como o processo de laminação controlada é realizado, sendo executada em três etapas de laminação, em diferentes temperaturas, seguidas de resfriamento acelerado ou em ar calmo.
Com base nessas condições, torna-se desnecessário realizar o tratamento térmico de normalização ao final do processo de laminação, garantindo-se tamanho de grão austenítico fino ou extrafino (MONTE, 2013). O procedimento de laminação e a adição de 
microligantes conferem ao aço API-5L X65 e demais microligados um ganho considerável nas propriedades mecânicas (COZZA et al., 2019).

As etapas de laminação consistem em:

- Primeiramente, ocorre a deformação e recristalização da austenita, promovendo o refino de grão a uma temperatura em torno de $1200^{\circ} \mathrm{C}$;

- A seguir, com a redução da temperatura para a casa dos $900^{\circ} \mathrm{C}$, a recristalização da austenita deixa de ocorrer, e o fenômeno de encruamento passa a se fazer presente, promovendo um aumento dos sítios disponíveis para nucleação da ferrita;
- Por fim, a segunda fase é repetida a uma temperatura inferior a $900^{\circ} \mathrm{C}$, causando o encruamento da austenita (como na fase anterior) e também da ferrita (PLAUT et al., 2009).

Essas três fases combinadas, com a adição de microligantes e o resfriamento acelerado, produzem uma microestrutura final típica de ferrita, perlita, bainita e/ou martensita. Para o resfriamento ao ar calmo, a microestrutura originada é ferrita e perlita. (PLAUT et al., 2009). Podem ser verificados, na figura 2 , os mecanismos de laminação controlada.

Figura 2 - Processo de laminação controlada de aços microligados

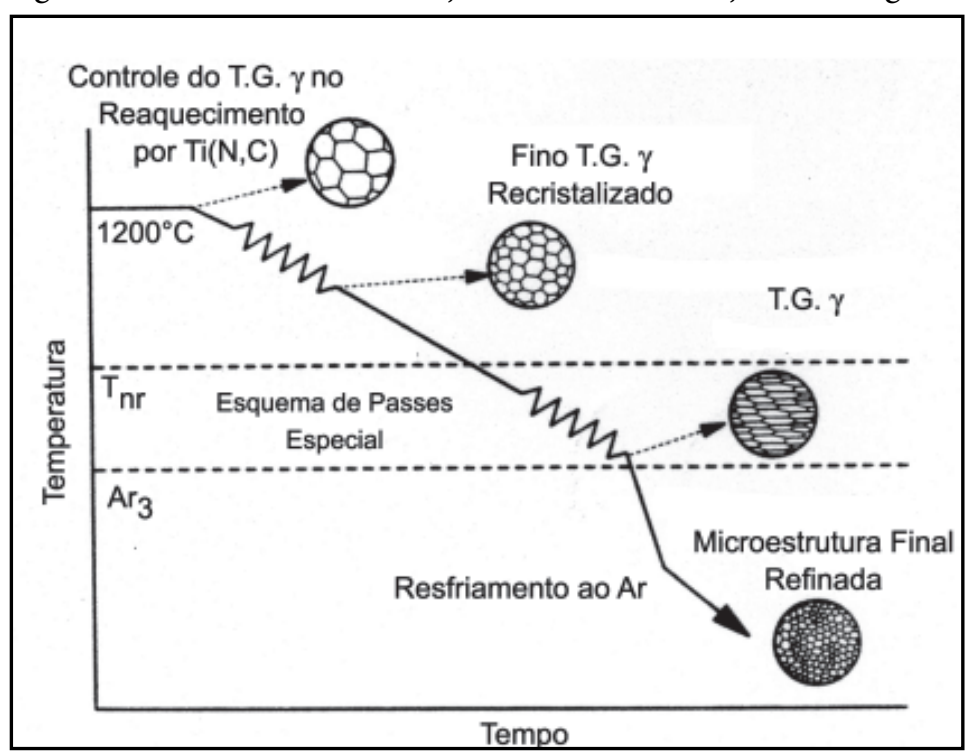

Fonte: Adaptado de Gorni e Mei (2003).

A adição de elementos microligantes é vantajosa para o processo de laminação controlada, uma vez que eles elevam a temperatura de não recristalização da austenita e isso reduz o trabalho mecânico do processo de laminação, ao possibilitar o trabalho com temperaturas mais elevadas (MONTE, 2013). O efeito do processo de conformação de chapas em tubos gera perdas no limite de escoamento do material, devido a um fenômeno chamado de efeito Bauschinger. O referido efeito ocorre, quando a tensão necessária para reverter à direção de deslizamentos é menor que a tensão que os provoca. Assim, os aços que apresentam microestrutura composta por ferrita e perlita possuem maior probabilidade de apresentar o efeito Bauschinger, todavia, aqueles que são compostos por ferrita acicular e precipitados finos, não se verifica o efeito (OGATA, 2009). Em geral, um aço que apresenta boa soldabilidade apresenta características mecânicas semelhantes tanto antes quanto depois de soldado, uma vez que o processo de soldagem, pode apresentar defeitos microestruturais que podem comprometer material. Devido a isso, é importante a preocupação com fatores como: as composições químicas do metal de base e do consumível; tensões residuais geradas pela solda; transformações produzidas na ZTA e o procedimento de soldagem empregado. A principal variável que define se um aço apresenta uma boa soldabilidade é o percentual de carbono equivalente a ele. Segundo a norma API, o carbono equivalente pode ser calculado por estas duas equações:

- Para aços com C > 0,12\%:

$$
C e q=\% C+\frac{\% M n}{6}+\frac{\%(C r+M o+V)}{5}+\frac{\%(N i+C u)}{15}
$$


- Para aços com $\mathrm{C}<0,12 \%$ :

$$
C e q=\% C+\frac{\% M n}{6}+\frac{\%(M n+C u+C r)}{30}+\frac{\% N i}{60}+\frac{\% M o}{15}+\frac{\% V}{10}+5 x \% B
$$

Quanto maior o percentual de carbono equivalente, menor será a soldabilidade do aço, uma vez que, nas altas temperaturas em que os processos de soldagem são realizados, existe a solubilidade do carbono e dos demais elementos constituintes do substrato que, devido à alta taxa de resfriamento, produz microestruturas frágeis nas regiões da ZTA e ZF. Em razão dos produtos, utilizados na indústria de óleo e gás, serem de expressiva necessidade e que as tubulações apresentem, além das características mecânicas já citadas, por vezes, é necessário considerável resistência à corrosão. Nesses casos, aços do tipo inoxidáveis que apresentam essas características, aliadas à resistência mecânica e tenacidade, podem ser utilizados, porém com elevado custo de produção. Com base nessas afirmações, o uso do processo de Cladding (CLAD) é uma alternativa viável para a indústria. $\mathrm{O}$ processo de CLAD é que o recobrimento do substrato com um metal que apresenta características diferentes e necessárias do metal base, com função de elevar a dureza superficial do material, conferir resistência à corrosão e propriedades tribológicas, como no o caso das tubulações de aço API-5L X65.

O comportamento dos aços microligados, submetidos aos processos de soldagem por fusão e, consequentemente associados à formação de ZTA e à Zona de fusão, está diretamente associado ao aporte térmico e às taxas de resfriamento aplicadas (COZZA et al., 2019). O efeito da soldagem é de elevada relevância em termos de microestrutura, microdureza e demais propriedades mecânicas. Os múltiplos ciclos térmicos têm influência nas transformações das microestruturas primárias e secundárias, podendo originar uma distribuição suave da microdureza nas diferentes regiões na ZTA e ZF. Deve ser destacado que na ZTA e na ZF podem ser observados diferentes constituintes, com morfologias, acicular, semi-equiaxada, poligonal e microestruturas críticas como ferrita delta, ferrita de widmastatten e dendritas (KAZASIDIS et al., 2021).

\section{Metodologia}

Foram realizadas soldagens de topo, utilizando os processos TIG e SMAW (eletrodo revestido) com revestimento CLAD. Os parâmetros, utilizados no processo de soldagem, estão identificados na tabela 1. A microscopia eletrônica de varredura (MEV) foi utilizada para observar a microestrutura das amostras e, nesse procedimento, foi empregado um microscópio eletrônico de varredura marca Olympus, modelo JSM-6610LV JEOL, observando-se a presença ou não de crescimento anormal de grão do aço microligado, junto a ZAC e ZF.

Tabela1 - Parâmetros de soldagem aplicados nos corpos de prova

\begin{tabular}{cccc}
\hline Soldagem & Consumível & Tensão (V) & Corrente (A) \\
\hline TIG & ER -NiCrMo-3 & 12 & 120 \\
Eletrodo revestido & ER -NiCrMo-3 & 25 & 95 \\
Revestimento CLAD & ER -NiCrMo-3 & 12 & 85 \\
\hline
\end{tabular}

Fonte: Os autores (2021).

A microdureza do material foi avaliada por um microdurômetro Vickers Shimadzu, modelo HMV $2 \mathrm{~T}$, utilizando carga com $0,3 \mathrm{~N}$ de força, durante 10 segundos.

Para a obtenção do perfil de microdureza, foram selecionados medições em 12 regiões situadas entre a superfície e o núcleo, no sentido radial da peça. Em cada região, foram obtidos os valores médios de cinco medidas, minimizando o efeito de segregações. $\mathrm{O}$ perfil de microdureza, associado ao metal base, ZTA e zona de fusão pode ser observado na figura 3. Com os dados obtidos, verificou-se o comportamento relativo ao efeito do aporte térmico nas transformações de fase nas regiões.

Os dados médios da microdureza também são importantes para verificação do comportamento da resistência mecânica, associados às microestruturas obtidas, durante a soldagem e revestimento. 
Figura 3 - Regiões onde foram realizados os ensaios de microdureza

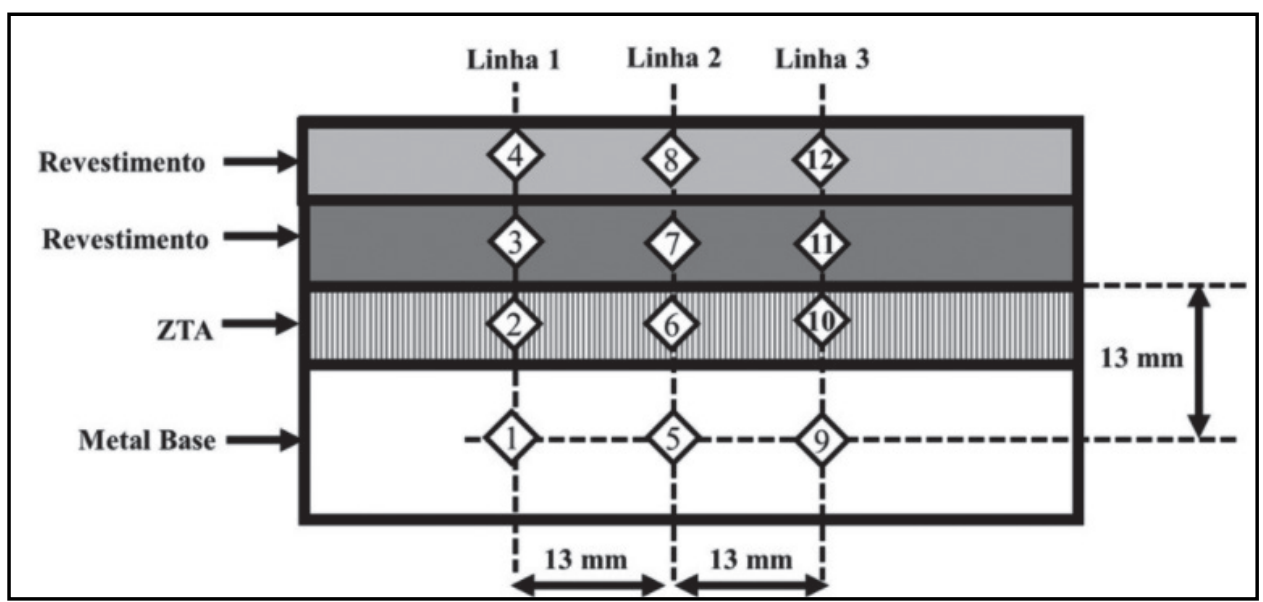

Fonte: Os autores (2021).

\section{Resultados e discussões}

\subsection{Análise microestrutural}

No substrato, o material apresentou microestrutura constituída basicamente por ferrita e perlita, com reduzido volume de bainita (B), sendo ela originada, durante o resfriamento controlado, após a laminação a quente (COZZA et al., 2019).

Através da análise microestrutural, verificou-se que a microestrutura na ZTA foi constituída de matriz ferrita $(\mathrm{F})$, perlita $(\mathrm{P})$ e martensita $(\mathrm{M})$ de baixo carbono, conforme indicado na figura 4 (a), e a ZF foi formada por martensita (M), bainita (B) e ferrita delta (FD) em (b).

Detectou-se na ZTA, o tamanho de grão austenítico 5 a 8 ASTM E112, verificando-se "ancoragem" do tamanho de grão classificado como fino (COZZA et al., 2019).

Figura 4 - Microestuturas verificadas na ZTA (a) e ZF (b)

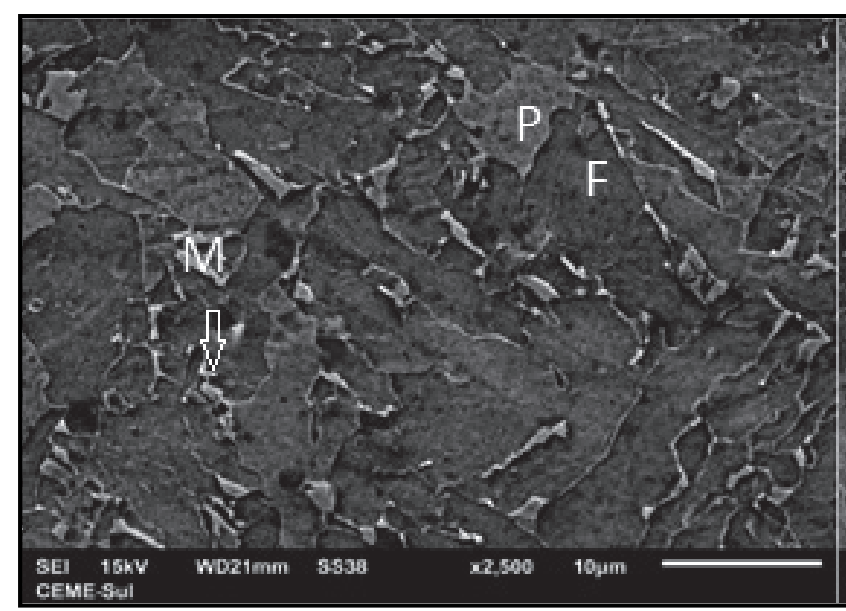

(a)

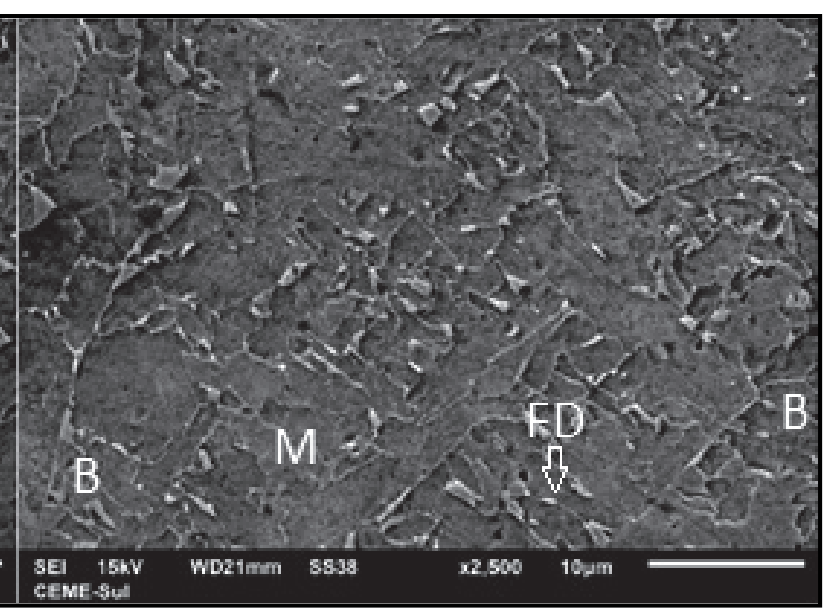

(b)

Fonte: Os autores (2021).

$\mathrm{Na} Z \mathrm{~F}$, o tamanho de grão austenítico foi classificado entre 4 a 6 ASTM E112, verificando-se crescimento anormal de grão, distribuído de forma heterogênea.
A presença de martensita e ferrita delta na ZF está diretamente relacionada ao aporte térmico, aplicado durante a soldagem, apresentando características intrínsecas ao processo de soldagem (KAZASIDIS et al., 2021). 


\subsection{Mapeamento da microdureza}

No mapeamento da microdureza, verificou-se comportamento homogêneo de microdureza no metal base e variações significativas na ZTA e ZF. Valores relacionados às regiões, identificadas na figura 3, podem ser visualizados na figura 5.

Figura 5 - Perfil de microdureza do metal base (1,5 e 9), ZTA (2,6 e 10) e ZF (3,4,7,8,11 e 12)

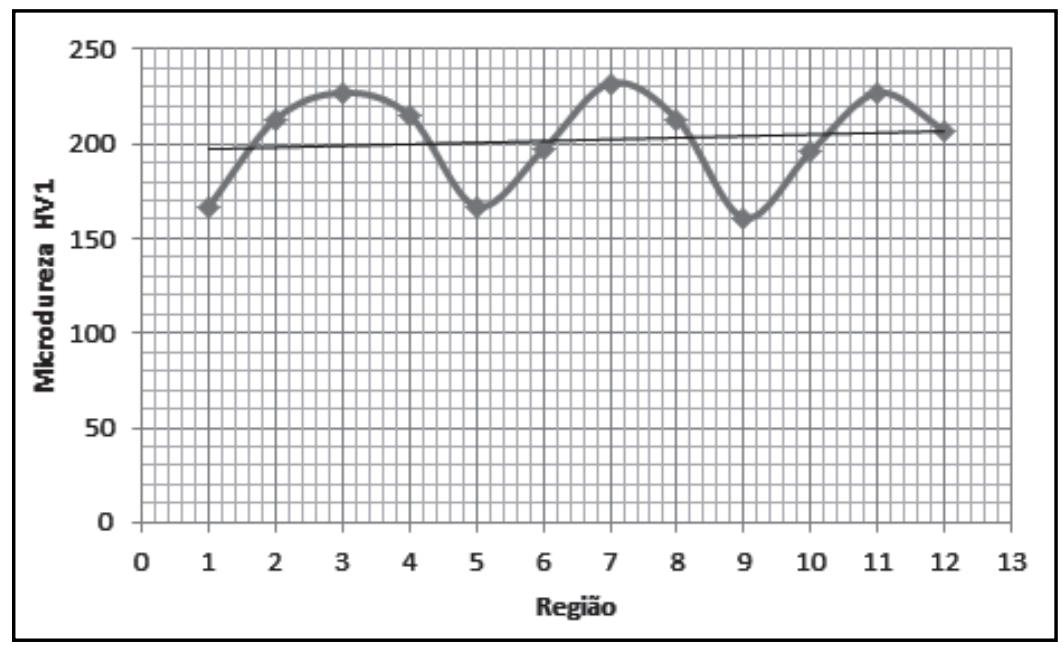

Fonte: Os autores (2021).

Os valores mais elevados de microdureza ocorreram na zona de fusão, sendo relacionados ao maior aporte térmico e taxas de resfriamento favorável à transformação martensítica (KAZASIDIS et al., 2021). Nas condições de energia de soldagem estudadas, observou-se a formação de uma região endurecida, ao se depositar apenas um cordão de solda, sendo que o valor de microdureza máxima e comprimento da região endurecida diminuíram com o aumento da energia de soldagem. Somente na região 2 , detectou-se valores de microdureza superiores a 200 HV1 na ZTA, sendo esse fenômeno, associado aos múltiplos passes aplicados que reduzem a taxa de resfriamento, inibindo a transformação martensítica. Não foram detectadas variações significativas nos valores médios de microdureza, obtidos em todas as regiões, sendo que os desvios padrões não foram significativos em relação ao perfil.

\subsection{Ensaios mecânicos}

Os corpos de provas, submetidos aos ensaios de tração, apresentaram valores de limite de resistência, limite de escoamento e alongamento similares aos encontrados no metal base. Verifica-se que as propriedades mecânicas, relacionadas ao aço microligado na ZAC, apresentam relevância associada à ancoragem do tamanho de grão austenítico. $\mathrm{Na}$ tabela 2, verificam-se os valores de limite de escoamento e de limite de resistência.

Tabela 2 - Resultados dos ensaios mecânicos, após processo de soldagem

\begin{tabular}{cccc}
\hline $\begin{array}{c}\text { Corpo } \\
\text { de prova }\end{array}$ & $\begin{array}{c}\text { Limite de } \\
\text { escoamento MPa }\end{array}$ & $\begin{array}{c}\text { Limite de } \\
\text { resistência MPa }\end{array}$ & $\begin{array}{c}\text { Localização } \\
\text { da fatura }\end{array}$ \\
\hline 1 & 438 & 591 & Metal de base \\
2 & 425 & 559 & Metal de base \\
3 & 430 & 571 & Metal de base \\
\hline
\end{tabular}

Fonte: Os autores (2021).

Junto à fratura, detectou-se microalvéolos coalescidos típicos de fratura dúctil, sendo esse comportamento o esperado, devido às características do metal base hipoeutetóide de baixo carbono (COZZA et al., 2019). 


\subsection{Morfologia do revestimento}

Verifica-se, na região do revestimento, que a deposição apresentou comportamento uniforme, não sendo detectadas gotas frias, tricas longitudinais transversais ou outros defeitos de sondagem, junto ao cordão de solda. Os dados foram referendados em ensaios não destrutivos de líquidos penetrantes. Na figura 6, observa-se a macrografia do metal base, zona termicamente e Zona de Fusão, a partir de corte transversal.

Figura 6 - Macrografia do cordão de solda na região de revestimento

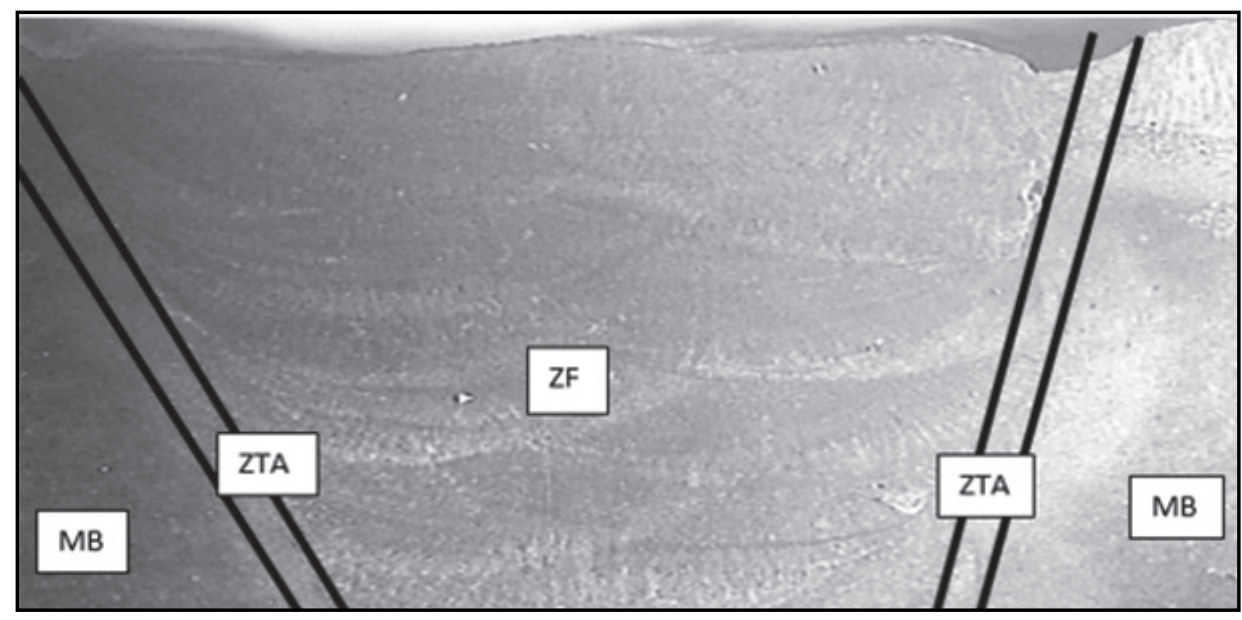

Fonte: Os autores (2021).

\section{Conclusões}

Os resultados obtidos, a partir da soldagem e revestimento do aço API 5 X 65, indicaram que não houve crescimento anormal de grão austenítico na ZTA.

O controle da intensidade da fonte e da taxa de resfriamento foi fundamental, para minimização do crescimento anormal de grão no aço microligado estudado na ZTA.

Já na região da ZF, detectou-se crescimento anormal de grão austenítico, relacionado ao aporte térmico aplicado, sendo que o metal de adição utilizado, não se caracteriza como microligado.

Os valores de microdureza mais elevados foram detectados na região de revestimento, apresentando zonas de transição ente o metal base, ZTA e ZF.

As microdurezas encontradas na ZTA e ZF em todas as amostras foram superiores às encontradas no metal base, contribuindo para que a ruptura dos ensaios de tração nessa região.Na ZTA, os valores foram minimizados pela aplicação dos múltiplos passes de soldagem.

O limite de escoamento médio foi de $431 \mathrm{MPa}$ e o limite de resistência médio de $573 \mathrm{MPa}$. Todas as amostras apresentaram ruptura no metal base, não apresentando influência direta do crescimento anormal de grão austenítico na ZF.
O conjunto apresentou resistência mecânica à tração satisfatória, para utilização nas operações em que o projeto demanda o aço API 5L X65.

A morfologia do revestimento mostrou-se uniforme e isento de defeitos de solidificação.

\section{Referências}

COZZA, L. M. et al. Escolha das energias de soldagem para aplicação na técnica da dupla camada na soldagem do aço ASTM 131 grau AH 36. Revista Soldagem e Inspeção, v. 20, p. 1-10, 2019. DOI: 10.1590/0104-9224/SI24.05.

GIORGETTI, V. et al. Stress corrosion craking and fatigue crack growth of an API 5 L X 70 welded joint in an ethanol environment. International Journal of Pressure Vessels and Piping, v. 169, p. 223-229, 2019. DOI: 10.1016/j.ijpvp.2019.01.006.

GORNI, A. A.; MEI, P. R. Aços alternativos ao HY80 sem a necessidade de aplicação de têmpera e revenimento. Metalurgia e Materiais, v. 56, p. 287293, 2003. DOI: 10.1590/S0370-44672003000400012.

KAZASIDIS, M. et al. Dissimilar welding between conventional and hight strengthn low alloy naval steel with the use of robotic metal core arc welding. The International Journal of Advanced Manufacturing 
Thechonology, v. 26, p. 2895-2907, 2021. DOI: 10.1007/s00170-021-06819-8.

MONTE, I. R. Caracterização microestrutural do aço API 5L X65 soldado por feixe de elétrons com diferentes aportes térmicos. 2013. 90 f. Dissertação (Mestrado em Ciências) - Universidade de São Paulo, Escola de Engenharia de Lorena, Lorena, 2013.

OGATA, P. H. Caracterização microestrutural do aço para tubo API 5L-X65 em diferentes regiões da chapa como laminada e após austenitização e resfriamento sob diversas taxas de resfriamento. 2009. 122 f. Dissertação
(Mestrado em Engenharia) - Universidade de São Paulo, São Paulo, 2009.

PLAUT, R. L. et al. Estudo das propriedades mecânicas do aço API X70 produzido por laminação controlada. Tecnologia em Metalurgia, Materiais e Mineração, v. 6, n. 1, p. 7-12, 2009. DOI: 10.4322/tmm.00601002.

SAEDI, A. H.; HAJJARI, E.; SADROSSADAT, S. M. Microstructural characterization and mechanical properties of TIG-Welded API 5L X60 HSLA steel and AISI 310S stainless steel dissimilar joints. Metallurgical and Materials Transactions A, v. 49, n. 11, p. 5497 5508, 2018. DOI: 10.1007/s11661-018-4890-y. 